\title{
Molecular analysis of an operon in Bacillus subtilis encoding a novel ABC transporter with a role in exoprotein production, sporulation and competence
}

\author{
Soile Leskelă, Vesa P. Kontinen and Matti Sarvas
}

Author for correspondence: Matti Sarvas. Tel: +358 04744 241. Fax: + 35804744347. e-mail: Matti.Sarvas@ktl.fi

National Public Health Institute, Department of Bacterial Vaccine Research and Molecular Bacteriology, Mannerheimintie 166, FIN-00300 Helsinki, Finland

\begin{abstract}
The levels of exoamylase and other exoenzymes of Bacillus subtilis are pleiotropically decreased by the ecs-26 (prs-26) and ecs-13 (prs-13) mutations. These mutations also cause a competence- and sporulation-deficient phenotype. In the present work, the ecs locus, which has been defined by the ecs-26 and ecs-13 mutations, was cloned and sequenced. Sequence analysis revealed a putative operon of three ORFs (ecsA, ecsB and ecsC). ecsA can encode a putative polypeptide of $\mathbf{2 4 8}$ amino acid residues containing an ATPbinding site. The polypeptide shows about $30 \%$ sequence similarity with the ATP-binding components of numerous membrane transporters of the ABC-type (ATP-binding cassette transporters or traffic ATPases). The ecs-26 mutation was found to result from a transition of one base pair changing the glycine ${ }_{164}$ of EcsA to a glutamic acid residue in the vicinity of the putative ATP-binding pocket. ecsB was predicted to encode a hydrophobic protein with six membrane-spanning helices in a pattern found in other hydrophobic components of ABC transporters. The properties deduced for the ecs $A$ and ecs $B$ gene products are consistent with the interpretation that ecs encodes a novel ABC-type membrane transporter of B. subtilis. The third ORF, ecsC, can encode a putative polypeptide of 237 amino acid residues. The polypeptide does not resemble components of $\mathrm{ABC}$ transporters.
\end{abstract}

Keywords: Bacillus subtilis, ecs operon, ABC transporter, secreted proteins

\section{INTRODUCTION}

The ATP-binding cassette (ABC) transporters (Hyde et al., 1990), alternatively called traffic A TPases (Ames et al., 1990), form a large family of membrane transporter systems or permeases found in both prokaryotic and eukaryotic cells (for reviews see Higgins, 1992, and Doige \& Ames, 1993). ABC transporters function in the import or export of a wide range of products such as proteins, peptides, polysaccharides, vitamins and drugs, utilizing ATP as the source of energy. In addition to the import or export of molecules, the function of an $\mathrm{ABC}$ transporter may be connected to the regulation of cellular functions

Abbreviation: $A B C, A T P$-binding cassette.

The EMBL accession number for the sequence reported in this paper is X87807. and signal transduction, such as the induction of sporulation, which is associated with oligopeptide transport in Bacillus subtilis (Rudner et al., 1991; Perego et al., 1991).

$\mathrm{ABC}$ transporters have a complex structure. In general, each transporter consists of two ATP-binding components and two highly hydrophobic components. Stoichiometrically, the different components are either in the form of homo- or heterodimers. The ATP-binding components are hydrophilic proteins which hydrolyse ATP to energize the transport. The ATP-binding components of all ABC transporters display extensive sequence homology that extends beyond the ATP-binding motifs (Higgins et al., 1986; Ames et al., 1990). The ATPase components are associated with the integral hydrophobic membrane protein components, which are presumed to form a transport channel (Kerppola et al., 1991; Higgins, 1992). In addition to the membranebound complex, bacterial transporters often contain other 
components. These include substrate-binding proteins in the case of several importers. The binding proteins are periplasmic in Gram-negative bacteria (Doige \& Ames, 1993) and peripheral lipoproteins of the cytoplasmic membrane in Gram-positive bacteria (Gilson et al., 1988; Alloing et al., 1990; Mathiopoulos et al., 1991; Perego et al., 1991; Rudner et al., 1991). Several bacterial exporters have been found to contain accessory membrane-bound proteins (Fath \& Kolter, 1993). The components of a bacterial transporter are often separate proteins encoded by one multicistronic operon, but may also be different domains of a single polypeptide, which is the structural arrangement found in eukaryotic $\mathrm{ABC}$ transporters (Higgins, 1992).

We have previously applied a mutant screen on $B$. subtilis to obtain non-conditional mutations affecting cellular components of the secretion machinery or the regulation of genes encoding secreted proteins. We have mutagenized a strain overexpressing secreted $\alpha$-amylase from the amyE gene of Bacillus amyloliquefaciens. Mutants have been isolated by screening for decreased levels of secreted $\alpha$-amylase and the identified mutations have been mapped in four different chromosomal loci (Kontinen \& Sarvas, 1988).

The ecs (effect on exoproteins, defect in competence and sporulation, previously called $p r s T$ ) locus was defined by two of these mutations, ecs-26 and ecs-13 (prs-26 and prs-13 in Kontinen \& Sarvas, 1988). The locus maps close to $g l y B$, on the other side of this marker than the $\operatorname{prs} A$ gene, which encodes a cellular component of the secretion machinery and was found in the same mutant screen as the ecs locus (Kontinen \& Sarvas, 1993). Both ecs mutants have a similar, pleiotropic phenotype. The level of the overexpressed heterologous $\alpha$-amylase was decreased to about $10 \%$ of the wild-type level in the culture medium. The secreted amounts of exoproteins expressed at a much lower level were also decreased by the ecs mutations, although only moderately. Such proteins are endogenous proteases, $\alpha$-amylase of $B$. subtilis and a heterologous $\beta$ lactamase. In addition, the mutants are not competent for transformation and their sporulation frequency is only $1 \%$ of that of the wild-type (Kontinen \& Sarvas, 1988).

The aim of the present study was to clone and sequence the ecs locus, and to characterize the ecs-26 mutation causing the pleiotropic phenotype.

\section{METHODS}

Bacterial strains, plasmids, growth conditions, and the plate assay of $\alpha$-amylase. Bacterial strains and plasmids used in this study are listed in Table 1. Unless otherwise indicated, strains were grown in L-broth, on L-agar or SMS-agar (Spizizen minimal medium; Anagnostopoulos \& Spizizen, 1961) plates containing glucose $\left(5 \mathrm{mg} \mathrm{ml}^{-1}\right)$, and supplemented with essential amino acids. Ampicillin $\left(100 \mu \mathrm{g} \mathrm{ml}^{-1}\right)$ or kanamycin $\left(10 \mu \mathrm{g} \mathrm{ml}^{-1}\right)$ were added as indicated. Secretion of $\alpha$-amylase was assayed with the plate method as described in Kontinen \& Sarvas (1988). The colonies were grown on L-agar plates containing $5 \%(\mathrm{w} / \mathrm{v})$ starch and the diameter of the clear halo around colonies was determined.
DNA techniques. Basic DNA techniques were those described in Sambrook et al. (1989). B. subtilis transformation was done as described in Gryczan et al. (1978). Chromosomal DNA was isolated from $B$. subtilis as described in Marmur (1961). For DNA sequencing, the dideoxy chain termination method of Sanger et al. (1977) and synthetic oligonucleotide primers were used.

Cloning of ecs locus. Since the ecs-26 mutant is not competent for transformation, we decided to clone the ecs-26 mutant locus to facilitate identification and analysis of recombinant clones. A lambda library of chromosomal fragments of the ecs-26 mutant (IH6821) was constructed as described in Kontinen et al. (1991) in the LambdaGEM-11 vector (Promega). The chromosomal fragments were produced by partial Sau3A digestion. The lambda library was screened by Southern hybridization with ${ }^{32}$ P-labelled plasmid pKTH3208 as a probe, which carries an approximately $2.3 \mathrm{~kb}$ insert of $B$. subtilis DNA and contains the glyB133 marker. The ecs-26 mutation is closely linked to the glyB133 marker (Kontinen \& Sarvas, 1988). The lambda clones which hybridized with the probe were tested for the presence of the ecs-26 mutation as follows. A glyB133 mutant (IH6531) carrying plasmid pKTH10, and therefore secreting large amounts of $\alpha$-amylase, was transformed with recombinant $\lambda$ DNA and transformants were selected for the ability to grow without glycine $\left(g l y^{+}\right)$. The presence of the ecs-26 mutation in the $g l y^{+}$transformants was tested by streaking single colonies onto starch plates (Kontinen \& Sarvas, 1988). The presence of the ecs26 mutation was identified by small haloes on those plates.

Computer analysis. GCG programs (Wisconsin Sequence Analysis Package, University of Wisconsin) were used for sequence analysis.

\section{RESULTS AND DISCUSSION}

\section{Cloning, subcloning and mapping of the ecs locus}

The ecs locus was cloned by constructing a LambdaGEM11 genome library of the ecs-26 mutant and screening for colonies which contained the $g l y B^{+}$marker. A lambda clone $(\lambda \mathrm{K} 10)$ containing an insert with the glyB133 marker was isolated and tested for the presence of the ecs-26 mutation as decribed (see Methods). About $60 \%$ of the $g y^{+}$transformants obtained were found to secrete $\alpha$ amylase at the low level characteristic of the ecs-26 mutant, indicating that the chromosomal insert in $\lambda \mathrm{K} 10$ contains both the glyB133 and ecs-26 markers.

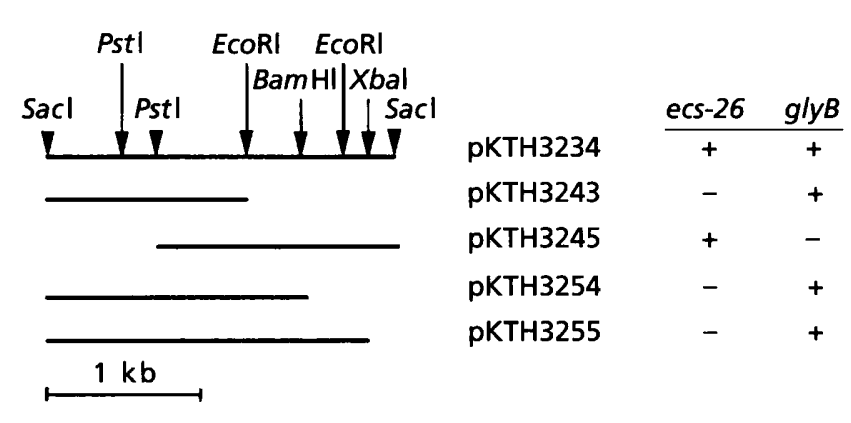

Fig. 1. Partial restriction map of the $2.3 \mathrm{~kb}$ Sacl fragment of pKTH3234 and inserts of the derivative plasmids (pKTH3243, pKTH3245, pKTH3254 and pKTH3255). The presence (+) or absence $(-)$ of ecs-26 or glyB $133^{+}$is shown in the right panel. 


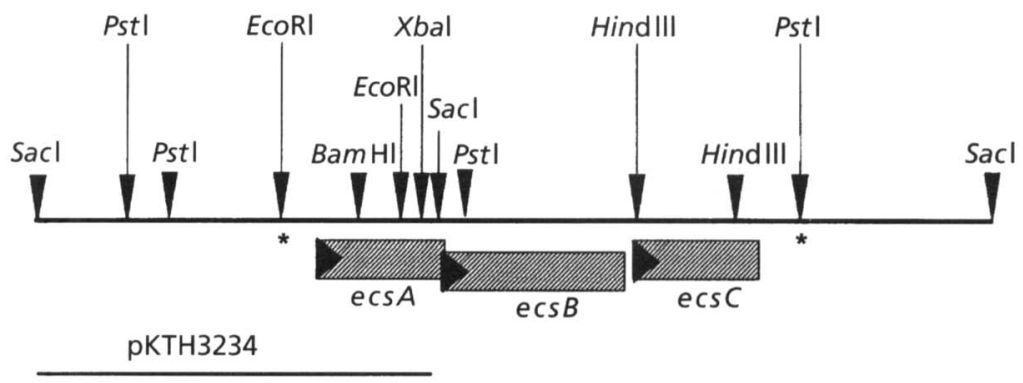

pKTH3270
Fig. 2. Partial restriction map of a $5.5 \mathrm{~kb}$ chromosomal DNA fragment from the ecs-26 mutant. The inserts of the subclones pKTH3234, pKTH3270 and pKTH3232 used for sequencing, and the orientation of the ORFs in the ecs operon are shown. The 3223 bp segment between the EcoRI and PstI sites indicated with asterisks was sequenced. The ecs-26 mutation is located at the $X b a l$ site.
The insert of $\lambda \mathrm{K} 10$ spans about $12 \mathrm{~kb}$ of the $B$. subtilis chromosome. This insert was digested with $\mathrm{SacI}$ and the resulting five fragments $(4.5 \mathrm{~kb}, 3.2 \mathrm{~kb}, 2.3 \mathrm{~kb}, 1.2 \mathrm{~kb}$ and $0.4 \mathrm{~kb})$ were subcloned into pGEM4Z. The subclones were tested for the presence of the ecs-26 mutation by congression (co-transformation with plasmid pKTH3211 carrying the $g l y B^{+}$marker). Subclone plasmids were introduced into strain IH6531 (glyB133, pKTH10). gly ${ }^{+}$ transformants were tested for the presence of the ecs-26 marker by screening for decreased secretion of $\alpha$-amylase in the plate assay. Plasmid pKTH3234, which carries the $2 \cdot 3 \mathrm{~kb} S a c \mathrm{I}$ fragment of $\lambda \mathrm{K} 10$, was found to contain the ecs-26 marker. No transformants of the desired phenotype (low $\alpha$-amylase secretion) were found with other subclone plasmids. Subsequently, we found that pKTH3234 transformed IH6531 to $g y^{+}$also in the absence of $\mathrm{pKTH} 3211$ $\left(g l y B^{+}\right)$DNA. About $20 \%$ of the $g y^{+}$transformants carried the ers -26 mutation. The $2.3 \mathrm{~kb}$ SacI fragment thus contains both the ecs-26 and the glyB133 site. Restriction fragments of this fragment were further subcloned into pGEM4Z and analysed for the presence of ecs-26 as above. The ecs-26 mutation was thus localized in the $200 \mathrm{bp}$ XbaI-SacI subfragment (Fig. 1).

\section{Nucleotide sequence of ecs}

We used three plasmid subclones obtained from $\lambda \mathrm{K} 10$ (pKTH3234, pKTH3270 and pKTH3232) as templates, and sequenced a 3223 bp EcoRI-PstI segment containing the ecs-26 mutation (Fig. 2) from both strands. The sequence is shown in Fig. 3.

Sequence analysis revealed that the ecs locus consists of three ORFs, ecs $A, \operatorname{ecs} B$ and $\operatorname{ccs} C$, in an arrangement indicative of an operon (Figs 2 and 3). A putative promoter (Fig. 3) was found upstream of $\operatorname{ecs} A$, with the sequence TTGATA-17bp-TTTTAT resembling the consensus promoter recognized by the $\delta^{\mathrm{A}}$ form of RNA polymerase (TTGACA-17bp-TATAAT; Moran et al., 1982). There is a putative rho-independent transcription terminator with a $\mathrm{GC}$-rich palindromic sequence, and a run of $\mathrm{T}$ residues downstream of ecsC. Each ORF is preceded by a putative ribosome-binding site (RBS); the two $3^{\prime}$ terminal codons of ecs $A$ overlap with the $5^{\prime}$ terminal codons of ecs $B$. A short intercistronic region is present between ecsB and ecsC. No other ORFs were identified, and translational stop codons are present in all reading frames in the sequences downstream and upstream of the putative operon.

To pinpoint the ecs-26 mutation, we studied a $4.5 \mathrm{~kb} \mathrm{SacI}$ fragment derived from the wild-type chromosome. It contained the glyB133 marker and had previously been subcloned from the $\lambda \mathrm{K} 3$ clone (Table 1) into pGEM4Z resulting in pKTH3267. The insert in pKTH3267 was characterized by restriction and sequence analysis. Sequence comparison revealed that the ecs- 26 mutation is a transition of $G_{738}$ to $A_{738}$. The mutation generated an $X b a \mathrm{I}$ restriction site and will result in $\mathrm{Gly}_{\mathbf{1 6 4}}$ to $\mathrm{Glu}_{\mathbf{1 6 4}}$ substitution in the putative Ecs A polypeptide.

\section{EcsA shows sequence similarity to $A B C$ transporters}

The ecs $A$ gene can encode a putative polypeptide of 248 amino acids. Comparison of the deduced amino acid sequence with proteins in the Swiss-Prot database showed about $30 \%$ sequence homology to a large number of ATP-binding proteins, which all belong to the superfamily of $\mathrm{ABC}$ transporters.

Sequence comparison shows that EcsA displays similarities with ATP-binding components of ABC-type transporters. The sequence alignment with three wellcharacterized ATP-binding proteins is shown in Fig. 4. First, the two motifs characteristic of ATP-binding proteins (Walker motifs I and II; Walker et al., 1982) are present. In addition, between the Walker motifs I and II, Ecs A contains a glutamine- and glycine-rich motif (consensus $\mathrm{L} / \mathrm{FSGGQQ/R/KQR)} \mathrm{that} \mathrm{is} \mathrm{well-conserved} \mathrm{in}$ the ATP-binding components of ABC-transporters (Ames et al., 1992). Homology that extends beyond the ATP-binding motifs was observed between Ecs A and $A B C$ transporters in the region of about 200 amino acid residues which also contains the putative motifs of the ATP-binding site. Such homology has not been observed between other ATP-binding proteins (Higgins et al., 1986; Hyde et al., 1990). Hydropathy analysis (Fig. 5a) showed that Ecs A is hydrophilic and has no evident membrane-spanning segments. This is a property shared by ATP-binding components of many bacterial ABCtransport systems in spite of their tight membraneassociation (Doige \& Ames, 1993). 
AATTCATCAATTCAGTGAAGAGAAATGGTTTGAGCATTGGACATGTTTATT'TTCTATCCAACTGTTTCTAAGACGTC'TTT GACAAACACCTCATTTTTTCAGTTGATATGCTTTTCCTCTACAACTTTTATGATGTCCACAACCCTGTCTCTTTATGACAG $-35$ $-10$

CAAATTCATCATTTGTTAAAAGGGAATTGTTTCAAATCAGGCCTTGITTTTGGTACTATGAAGAAAAACACTATAAGGGG AGAAACTATGTCTCTGCTATCGGTAAAAGACTTGACCGGCGGATATACAAGGAATCCGGTTTTAAAAAACGTATCATTCA

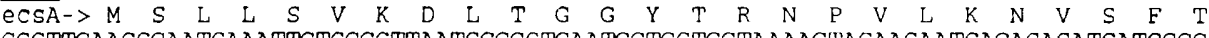
CCCTTGAACCGAATCAAATTGTCGGCTTAATCGGGCTGAATGGTGCTGGTAAAAGTACAACAATCAGACACATCATCGGG

$\begin{array}{lllllllllllllllllllllllllllllll}L & E & P & N & Q & I & V & G & L & I & G & L & N & G & A & G & K & S & T & T & I & R & H & I & I & G\end{array}$ CTGATGGACCCGCATAAAGGTTCAATCGAATTAAACGGTAAAACGTTTGCTGAGGATCCGGAAGGCTACCGTTCACAATT $\begin{array}{lllllllllllllllllllllllllll}L & M & D & P & H & K & G & S & I & E & L & N & G & K & T & F & A & E & D & P & E & G & Y & R & S & Q & F\end{array}$ TACCTATATACCTGAAACACCTG'TTTTATACGAAGAATTGACGCTGATGGAGCATCTTGAACTAACAGCCATGGCATATG GACTGTCAAAAGAAACGA'TGGAGAAAAGGC'I'GCC'TCCGCTACTAAAGGAATTCCGAATGGAAAAGAGGCTGAAGTGGI"IC

$\begin{array}{llllllllllllllllllllllllllll}L & S & K & E & T & M & E & K & R & L & P & P & L & L & K & E & F & R & M & E & K & R & L & K & W & F\end{array}$ CCGGCCCATTTTTCTAAAGGAATGAAGCAGAAGGTTATGATTATGTGCGCATTT'TrTGGCAGAGCCTGCGCTCTACATTAT $\begin{array}{lllllllllllllllllllllllllllllllll}P & A & H & F & S & K & G & M & K & Q & K & V & M & I & M & C & A & F & L & A & E & P & A & L & Y & I & I\end{array}$ TGATGAGCCTTTTCTAGGGCTTGATCCGCT"TGCCAT"IAACGCGCTGCTTGAACGGATGAATGAAGCGAAAAAAGGCGGGG $\begin{array}{llllllllllllllllllllllllllll}D & E & P & F & L & G & L & D & P & L & A & I & N & A & L & L & E & R & M & N & E & A & K & K & G & G & A\end{array}$ CGAGCGTGCTGATGTCAACACACATTTTGGCAACGGCAGAACGCTATTGCGATTCGTTTATTATTTTACATAACGGCGAG

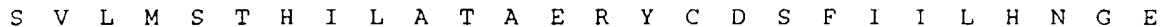
GTGCGGGCGCGCGGCACGCTGTCAGAGCTCAGAGAGCAGTTTGGAATGAAGGACGCGGCGCTGGACGATTTGTATCTTGA

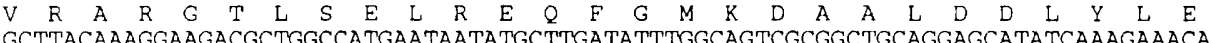

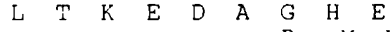

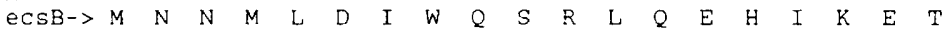
AGAACATACATGAAATATATGCTCAACGATCACCICG'TCATTGTTTIIGATTTTTTTTCTAGCGGGCGCTGCAAGCTGGTA

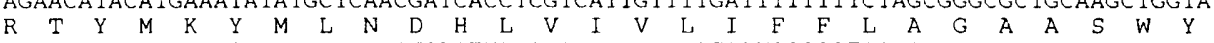
CAGCAAATGGATACGGGACATTCCCGCTCACTTTCCGTCCTT'TGGGTGATGGCCGTGCTG'TTTTCGCTCGTATTGACAA

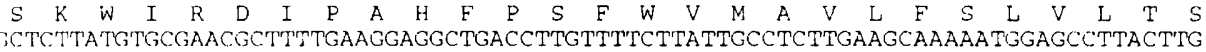

$\begin{array}{llllllllllllllllllllllllllllllllll}S & Y & V & R & T & L & L & K & E & A & D & L & V & F & L & L & P & L & E & A & K & M & E & P & Y & L\end{array}$ AAGCAGGCGTTTGTCTACAGCTATGTGTCTCAGCTGTTTCCGCTGATTGCGCTGAGCATCGTTGCGATGCCGCTITIATTT $\begin{array}{lllllllllllllllllllllllllllllllllll}K & Q & A & F & V & Y & S & Y & V & S & Q & L & F & P & L & I & A & L & S & I & V & A & M & P & \text { L } & Y & F\end{array}$ CGCAGTCACTCCGGGAGCTTCGCTCGTATCGTATGCCGCGGTCTTTGTCCAACTGTTGCTGCTGAAAGCGTGGAATCAGG

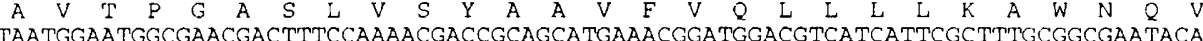
$\begin{array}{llllllllllllllllllllllllllllll}M & E & W & R & T & T & F & Q & N & D & R & S & M & K & R & M & D & V & I & I & R & F & A & A & N & T\end{array}$ CTCGTTCTTTATTTTCTTTTCCAATCTGTTTATATGTATGCGCTTCTCGTCTATGTCATTATGGCTG'T'TCTIPTATCTGTA $\begin{array}{lllllllllllllllllllllllllllll} & V & L & Y & F & V & F & Q & S & V & Y & M & Y & A & L & L & V & Y & V & I & M & A & V & L & Y & I & Y\end{array}$ TATGTCTTCCGCAGCAAAACGGAAAACATTTAAATGGGAGAGCCATATTGAGTCCGAATTGAGACGAAAGCAGCGTTTCT $\begin{array}{lllllllllllllllllllllllllll}M & S & S & A & A & K & R & K & T & F & K & W & E & S & H & I & E & S & E & L & R & R & K & Q & R & F & Y \\ M & & \end{array}$ ATCGGATTGCCAACCTGTTTACTGATGTGCCGCATTTGCGAAAGCAAGCCAAACGCAGAGCTTATCTCCAC

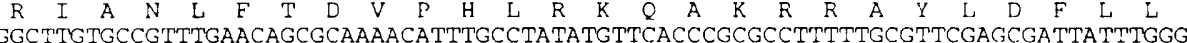
R L V F F E O R T F A Y M F T R A F L K S S D Y L G

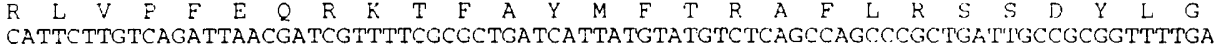
$\begin{array}{lllllllllllllllllllllllllllllllllll}I & L & V & R & L & T & I & V & F & A & L & I & I & M & Y & V & S & A & S & P & L & I & A & A & V & L & T\end{array}$ C'TGTGT'TTGCCATTTTCATTACGGGCA'II'CAGCTTCTGCCGCTCTTCGGTCACTTTGACCATCTGGCGCTTCAAGAGCTG

$\begin{array}{lllllllllllllllllllllllllllllll}V & F & A & I & F & I & T & G & I & Q & L & L & P & L & F & G & H & F & D & H & L & A & L & Q & E & L\end{array}$ TACCCTGTGCAAAAAGAAACAAAGCTGAAAAGCTA T"I"TCTCTCTATTAAAAACTGCACT"I'AGTATTCAAGCGCTGCTGAT

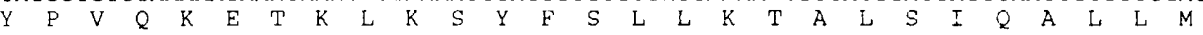
GTCTGTTGCATCTGCCTATGCAGCCGGCTTGACCGGTTPTCTGTACGCGCTGATCGGTTCTGCCGTTCTGATTTTTGTTG $\begin{array}{lllllllllllllllllllllllllll}S & V & A & S & A & Y & A & A & G & L & T & G & F & L & Y & A & L & I & G & S & A & V & L & I & F & V & V\end{array}$ 'I'I'T"IGCC'IGCT"I'A I'A TGACGACCAGGCTGAAAAAGCACGGAAAGCTGTGAACTGAAAAGAGGTAATCAAA TGACAGATAA

$\begin{array}{lllllllllllllllllllllll}L & P & A & Y & M & T & T & R & L & K & K & H & G & K & L & - & \text { eCSC }>M & T & D & N\end{array}$ TCAGCTGCTGA TGCAGGAAGCT'TTGGAATGGAAAATGCATT'T'TTTGCGAAAGGA TTCCATGTTTGAACGCTT'TTCGAAGC $\begin{array}{lllllllllllllllllllllllllll}Q & L & L & M & Q & E & A & L & E & W & K & M & H & F & L & R & K & D & S & M & F & E & R & F & S & K & R\end{array}$ GTGTCCAGACGAAGGTGAATGAACGGATTCCTGAAAAAATCCATACGGTCGTCACCGAGAGTGTGAAAAAAATGGTAGAA $\begin{array}{llllllllllllllllllllllllll}V & Q & T & K & V & N & E & R & I & P & E & K & I & H & T & V & V & T & E & S & V & K & K & M & V & E\end{array}$ GCGACAATGGCCGGCTCTAATATCATCACCTATAAAAAGGATACAAGTGCACTGTCGCTCAGTGAAAAAAACGAATTGGC

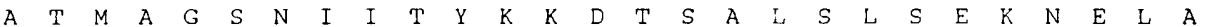
GAAAAAAACGATTGTTTCTTATCAAAAAGTGGCAGCTGCTGAGGGAGTCGGCACCGGAGCGGGCGGCATTTTTTTTAAGCA

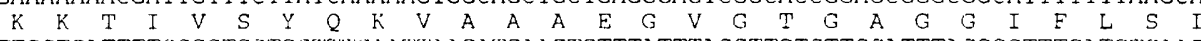
T'TGCTGATTTTCOGCTGCTGCI'I"ICAATI'IAAGATGAAGTGTTTATTTACCTIGTCTTCCATTTACGGCTTTGA TCTCAAG \begin{tabular}{llllllllllllllllllllllllll}
$A$ & $D$ & $F$ & $P$ & $L$ & $L$ & $L$ & $S$ & $I$ & $K$ & $M$ & $K$ & $C$ & $L$ & $F$ & $T$ & $L$ & $S$ & $S$ & $I$ & $Y$ & $G$ & $F$ & $D$ & $V$ & $K$ \\
\hline
\end{tabular} L L F Q L A F S S D D O R K S L F S L

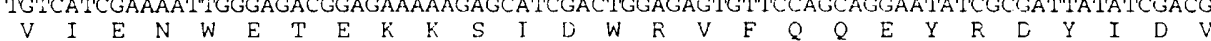
TCGTGAAGCTTTTTCAGCTTTTGCCGGGCG'IAGGAGCGGCAGTCGGCGGAATT'TGCCAATTATAAGCTGCTTGCTCAGCT"I $\begin{array}{llllllllllllllllllllllllll}V & K & L & F & Q & L & L & P & G & V & G & A & A & V & G & G & I & A & N & Y & K & L & L & A & Q & L\end{array}$ GGAGAAACGGCAAGACATGTTTTTCATCTGAGGATATTAAAGGAAACAGCCGGAGAATAAACACTCCGGCTGTTTTTTTTA. $G$ E $T$ T $A$ A $R$ H

TAGCTGATGATAGGTGATCGCAGCGCCGGCAAGCACCTTGGCCGCTGTCAGCATGGCTTTTTCGTTGATATCAAATTTCG GATGGTGGTGGGAATAGACTCGCTCTGGCTGTTCGGGAGCGGCGCCTGTAAAGAAAAAAGTGCCCTTCACGTTTTTGTAAO TAATAAGCAAAATCCTCGCCGCCCATTITGGGTTCACCGTCAATGACCTGCTGAACGCCCTCGGTAT"ICI"I"IGCGGTGCT CACCAAGTGGTTCGTTTCTGCAG

Fig. 3. Nucleotide sequence of the ecs operon. Deduced amino acid sequences of the three ORFs of the ecs operon (ecsA, ecs $B$ and ecs $C$ ) are shown below the nucleotide sequence. Putative promoter sequences are indicated as -10 and -35 . RBSs preceding the start codon of each ORF are underlined. Arrows below the sequence mark the stem-loop structure of the transcription termination site. In the ecsA26 mutant, the $G_{738}$ (bold letter) was replaced by $A_{738}$. This mutation changes $\mathrm{Gly}_{164}$ (bold letter) of EcsA to Glu ${ }_{164}$. 
Table 1. Bacterial strains and plasmids

\begin{tabular}{|c|c|c|}
\hline Strain/plasmid & Characteristics & Reference/source \\
\hline \multicolumn{3}{|l|}{ Strain } \\
\hline \multicolumn{3}{|l|}{ E. coli } \\
\hline TGI & supE bsd $\Delta 5$ thi $\Delta($ lac-pro $A B) \mathrm{F}^{\prime}\left[\operatorname{traD} 36\right.$ pro $A B^{+}$lacl ${ }^{\mathrm{q}}$ lacZ $\left.\Delta \mathrm{M} 15\right]$ & Sambrook et al. (1989) \\
\hline \multicolumn{3}{|l|}{ B. subtilis } \\
\hline IH6821 & ecs $A 26$ (pKTH10) (re-isolation from culture stock) & Kontinen \& Sarvas (1988) \\
\hline IH6531 & glyB133 bis $A 1 \operatorname{trp} C 2(\mathrm{pKTH} 10)$ & Kontinen \& Sarvas (1988) \\
\hline \multicolumn{3}{|l|}{ Plasmid } \\
\hline pGEM4Z & $A p^{r}, l a c Z$ & Promega \\
\hline pKTH10 & $\mathrm{Km}^{r}$, pUB110-derivative carrying $\alpha$-amylase gene of $B$. amyloliquefaciens & Palva (1982) \\
\hline pKTH3208 & glyB133+, pJH101 carrying a $2.3 \mathrm{~kb} \mathrm{BamHI-HindIII} \mathrm{fragment} \mathrm{of} \mathrm{pKTH3267}$ & This study \\
\hline pKTH3211 & gly $\mathrm{B}_{133^{+}}$, pGEM4Z carrying a $2.3 \mathrm{~kb}$ BamHI-HindIII fragment of pKTH3267 & This study \\
\hline pKTH3232 & pGEM $4 Z$ containing a $3.2 \mathrm{~kb} S a c \mathrm{I}$ fragment of $\lambda \mathrm{K} 10$ & This study \\
\hline pKTH3234 & $e c s A 26$, pGEM4Z carrying a $2.3 \mathrm{~kb}$ Sac I fragment of $\lambda \mathrm{K} 10$ & This study \\
\hline pKTH3267 & $g l y B 133^{+}$and $e c s A 26^{+}$, pGEM $4 Z$ carrying a $4.5 \mathrm{~kb}$ Sac I fragment of $\lambda \mathrm{K} 3^{*}$ & This study \\
\hline pKTH3270 & ecs $A 26$, pGEM4Z containing a $1.7 \mathrm{~kb}$ EcoRI-HindIII fragment of $\lambda \mathrm{K} 10$ & This study \\
\hline
\end{tabular}

*'The $\lambda \mathrm{K} 3$ was isolated from a wild-type chromosomal library (Kontinen et al., 1991).

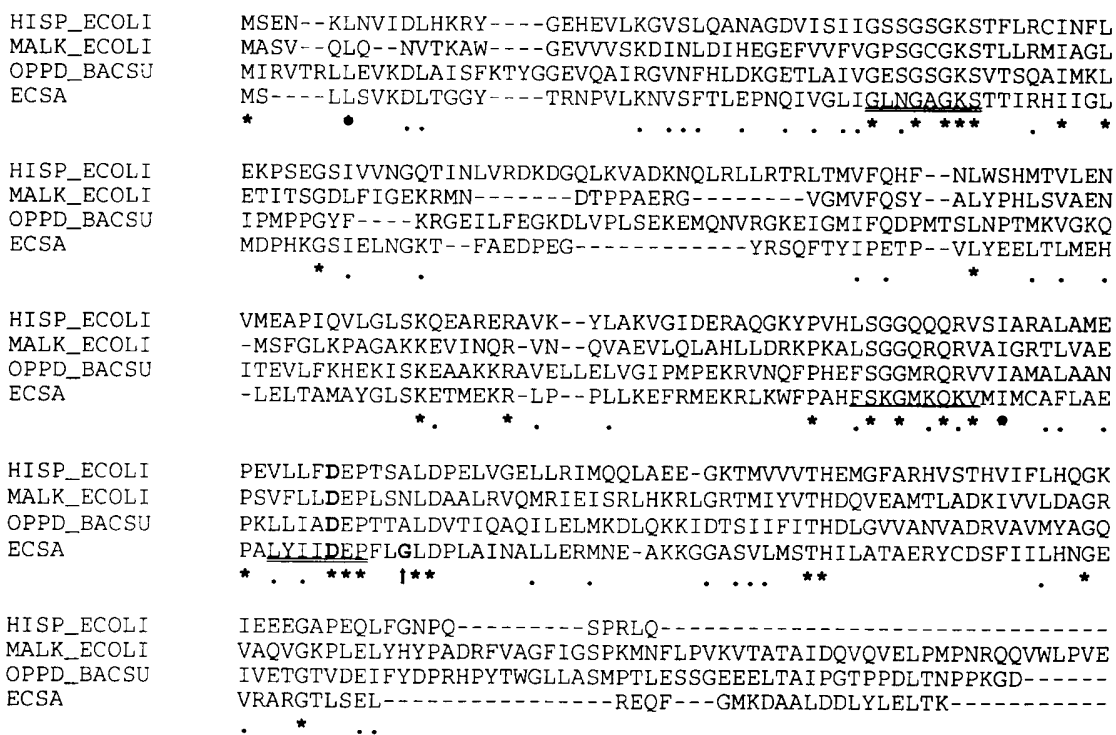

PEVLLFDEPTSALDPELVGELLRIMQQLAEE-GKTMVVVTHEMGFARHVSTHVIFLHQGK PSVFLLDEPLSNLDAALRVQMRIEI SRLHKRLGRTMI YVTHDQVEAMTLADKIVVLDAGR PKLLI ADEPTTALDVTIQAQ I LELMKDLQKK I DTS I I I THDLGVVANVADRVAVMYAGO PALYIDERFLGLDPLAINALLERMNE-AKKGGASVLMSTH I LATAERYCDSF I ILHNGE

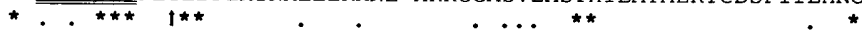

IEEEGAPEQLFGNPQ- VAQVGKPLELYHY PADRFVAGF IGSPKMNFL PVKVTATA IDQVQVELPMPNRQQVWLPVE IVETGTVDEI FYDPRHPYTWGLLASMPTLESSGEEELTAI PGT P PDLTNPPKGD- - - - -

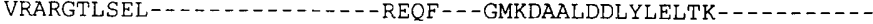
*

Fig. 4. Alignment of EcsA and ATP-binding components of three bacterial $A B C$ transporters: HisP of Escherichia coli (Kraft \& Leinwand, 1987), MalK of $E$. coli (Gilson et al., 1982) and OppD of B. subtilis (Perego et al., 1991, Rudner et al., 1991). The alignment does not extend to the C-termini of the polypeptides. The two ATP-binding motifs (Walker et al., 1982) are double-underlined and the glycine/glutamine-rich sequence (Ames et al., 1992) is underlined. Identical and related amino acids are shown by asterisks and dots, respectively. The highly conserved aspartic acid (D) is in bold. The arrow points to the ecsA26 mutation site.
The sequence comparison leaves little doubt about the nature of Ecs A as an A TP-binding component. The point mutation, $\operatorname{ecs} A 26$, is also consistent with this conclusion. The mutation replaces $\mathrm{Gly}_{164}$ with a charged residue (Glu) close to the C-terminus of the Walker II motif of the ATP-binding site (Fig. 4) and could thus affect ATP binding.

\section{EcsB and EcsC}

$\operatorname{ecs} B$ and $\operatorname{ecs} C$ are predicted to encode polypeptides of 409 and 237 amino acid residues, respectively. No proteins showing significant homology with these proteins were found in the Swiss-Prot database.

In contrast to the ATP-binding component, hydrophobic components of $\mathrm{ABC}$ transporters do not show extensive amino acid sequence homology. However, structural similarities can be found (Kerppola \& Ames, 1992; Higgins, 1992). Studies on the topology of hydrophobic components have revealed a pattern of several membranespanning peptides with intervening periplasmic and cytoplasmic loops. Hydropathy profiles suggest a similar topology for a large number of hydrophobic components of $A B C$ transporters. The structural homology is most striking in the C-terminal parts of the proteins (Kerppola \& Ames, 1992). Most of the transporters are predicted to contain six transmembrane segments per hydrophobic component (Higgins, 1992), but the minimum structure has been proposed to consist of five membrane-spanning helices (Kerppola \& Ames, 1992). In the case of large proteins, additional membrane spanners and loops can be found in the $\mathrm{N}$-terminal end of the protein. 


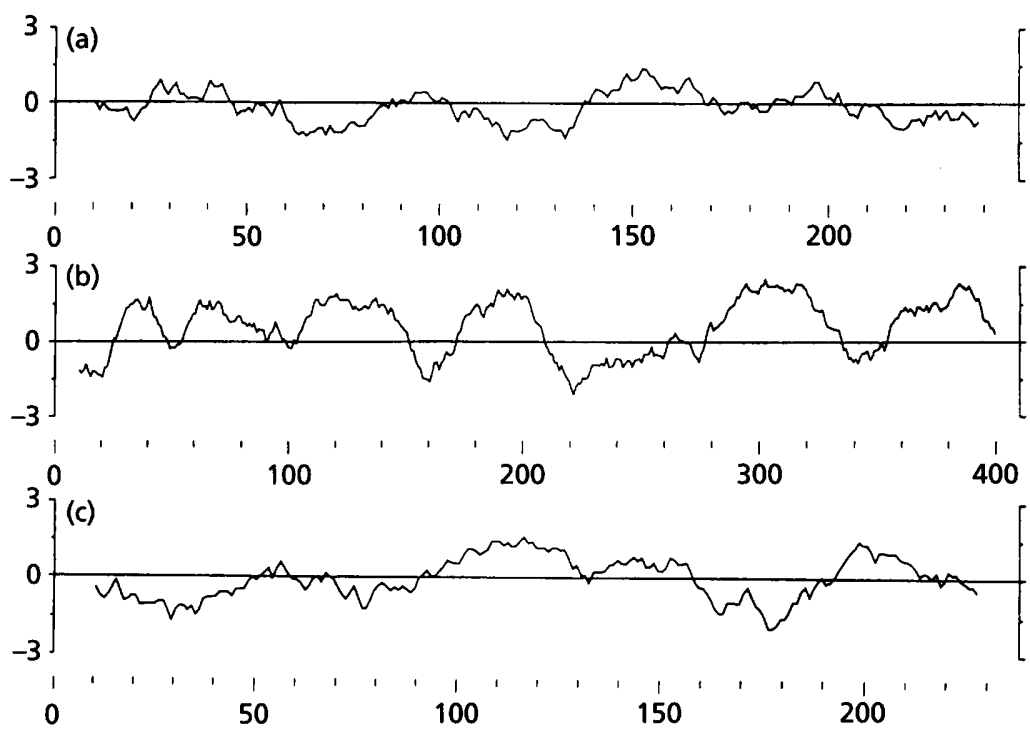

Figure 5. Hydrophobicity plot of (a) EcsA, (b) EcsB and (c) EcsC according to Kyte \& Doolittle (1982) with the window of 20 amino acid residues. Hydrophobic sequences point upwards.
Hydropathy analysis (Kyte \& Doolittle, 1982) of EcsB showed six highly hydrophobic regions characteristic of membrane-spanning segments (Fig. $5 \mathrm{~b}$ ). According to the algorithm described in Eisenberg et al. (1984), the hydrophobic segments were predicted to contain one membrane-spanning helix each. A large hydrophilic and charged loop could be identified in the C-terminal part of EcsB. The predicted structural features of EcsB fit to those of a hydrophobic component of an $\mathrm{ABC}$ transporter. The hydropathy analysis of the EcsC polypeptide (Fig. 5c) also showed the presence of hydrophobic segments, but none of the algorithms used predicted the presence of membrane-spanning helices. Furthermore, the overall structural pattern is very different from that of EcsB or that of the hydrophobic components of $\mathrm{ABC}$ transporters. Therefore, the structural predictions do not give an indication that $\mathrm{Ecs} C$ is a second hydrophobic component of the putative $A B C$ transporter. Clearly, EcsC neither contains a signal sequence nor the consensus cleavage site of a lipoprotein signal peptide (Hayashi \& Wu, 1990). Thus, there is no indication of EcsC being a lipoprotein, such as the binding protein found in the importers of $B$. subtilis (Mathiopoulos et al., 1991; Perego et al., 1991; Rudner et al., 1991; Woodson \& Devine, 1994), importers of other Gram-positive organisms (Alloing et al., 1990), or the accessory component found in the subtilin exporter of B. subtilis (Chung et al., 1992; Klein et al., 1992).

The properties deduced for the ecs $A$ and ecs $B$ gene products strongly suggest that they form an $A B C$ transporter. The role of this transporter in the production of the secreted proteins, in sporulation and competence which are affected pleiotropically by ecs mutations, remains to be elucidated.

\section{ACKNOWLEDGEMENTS}

We thank Dr Ilkka Palva and Dr Marko Lauraeus for valuable comments and discussions, and Dr Burke Zimmerman for critical reading of the manuscript. This study was financially supported by Academy of Finland and by Technology De- velopment Center (TEKES) and is a part of the EEC contract BIO2-CT93-0254.

\section{REFERENCES}

Alloing, G., Trombe, M.-C. \& Claverys, J.-P. (1990). The ami locus of the Gram-positive bacterium Streptococcus pneumoniae is similar to binding protein-dependent transport operons of Gram-negative bacteria. Mol Microbiol 4, 633-644.

Ames, G. F.-L., Mimura, C. S. \& Shyamala, V. (1990). Bacterial periplasmic permeases belong to a family of transport proteins operating from Escherichia coli to human: traffic ATPases. FEMS Microbiol Rev 75, 429-446.

Ames, G. F.-L., Mimura, C. S., Holbrooks, S. R. \& Shyamala, V. (1992). Traffic ATPases: a superfamily of transport proteins operating from Escherichia coli to humans. Adv Enzymol 65, 1-47.

Anagnostopoulos, C. \& Spizizen, J. (1961). Requirements for transformation of Bacillus subtilis. J Bacteriol 81, 741-746.

Chung, Y. J., Steen, M. T. \& Hansen, J. N. (1992). The subtilin gene of Bacillus subtilis ATCC 6633 is encoded in an operon that contains a homolog of the hemolysin B transport protein. $J$ Bacteriol 174, $1417-1422$.

Doige, C. A. \& Ames, G. F.-L. (1993). ATP-dependent transport systems in bacteria and humans: relevance to cystic fibrosis and multidrug resistance. Annu Rev Microbiol 47, 291-319.

Eisenberg, D., Schwarz, E., Komaromy, M. \& Wall, R. (1984). Analysis of membrane and surface protein sequences with the hydrophobic moment plot. J Mol Biol 179, 125-142.

Fath, M. J. \& Kolter, R. (1993). ABC transporters: bacterial exporters. Microbiol Rev 57, 995-1017.

Gilson, E., Nikaido, H. \& Hofnung, M. (1982). Sequence of the malK gene in E. coli K12. Nucleic Acids Res 10, 7449-7458.

Gilson, E., Alloing, G., Schmidt, T., Claverys, J.-P., Dudler, R. \& Hofnung, M. (1988). Evidence for high affinity binding-protein dependent transport systems in Gram-positive bacteria and in Mycoplasma. EMBO J 7, 3971-3974.

Gryczan, T., Contente, S. \& Dubnau, A. (1978). Characterization of Stapbylococcus aureus plasmids introduced by transformation into Bacillus subtilis. J Bacteriol 134, 318-329. 
Hayashi, S. \& Wu, H. C. (1990). Lipoproteins in bacteria. J Bioenerg Biomembr 22, 451-471.

Higgins, C. F. (1992). ABC transporters: from microorganisms to man. Annu Rev Cell Biol 8, 67-113.

Higgins, C. F., Hiles, I. D., Salmond, G. P. C., Gill, D. R., Downie, J. A., Evans, I. J., Holland, I. B., Gray, L., Buckel, S. D., Bell, A. W. \& Hermodson, M. A. (1986). A family of related ATP-binding subunits coupled to many distinct biological processes in bacteria. Nature 323, 448-450.

Hyde, S. C., Emsley, P., Hartshorn, M. J., Mimmack, M. M., Gileadi, U., Pearce, S. R., Gallagher, M. P., Gill, D. R., Hubbard, R. E. \& Higgins, C. F. (1990). Structural model of ATP-binding proteins associated with cystic fibrosis, multidrug resistance and bacterial transport. Nature 346, 362-365.

Kerppola, R. E. \& Ames, G. F.-L. (1992). Topology of the hydrophobic membrane-bound components of the histidine periplasmic permease. J Biol Chem 267, 2329-2336.

Kerppola, R. E., Shyamala, V. K., Klebba, P. \& Ames, G. F.-L. (1991). The membrane-bound proteins of periplasmic permeases form a complex. J Biol Chem 266, 9857-9865.

Klein, C., Kaletta, C., Schnell, N. \& Entian, K.-D. (1992). Analysis of genes involved in biosynthesis of the lantibiotic subtilin. Appl Environ Microbiol 58, 132-142.

Kontinen, V. P. \& Sarvas, M. (1988). Mutants of Bacillus subtilis defective in protein export. J Gen Microbiol 134, 2333-2344.

Kontinen, V.P. \& Sarvas, M. (1993). The PrsA lipoprotein is essential for protein secretion in Bacillus subtilis and sets a limit for high-level secretion. Mol Microbiol 8, 727-737.

Kontinen, V. P., Saris, P. \& Sarvas, M. (1991). A gene (prsA) of Bacillus subtilis involved in a novel, late stage of protein export. Mol Microbiol 5, 1273-1283.

Kraft, R. \& Leinwand, L. (1987). Sequence of the complete P protein gene and part of the $M$ protein gene from the histidine transport operon of Escherichia coli compared to that of Salmonella typhimurium. Nucleic Acids Res 15, 8568.

Kyte, J. \& Doolittle, R. F. (1982). A simple method for displaying the hydropathic character of a protein. $J$ Mol Biol 157, 105-132.
Marmur, J. (1961). A procedure for the isolation of deoxyribonucleic acid from micro-organisms. $J$ Mol Biol 3, 208-218.

Mathiopoulos, C., Mueller, J. P., Slack, F. J., Murphy, C. G., Patankar, S., Bukusoglu, G. \& Sonenshein, A. L. (1991). A Bacillus subtilis dipeptide transport system expressed early during sporulation. Mol Microbiol 5, 1903-1913.

Moran, C. P., Lang, N., LeGrice, S. F. J., Lee, G., Stephens, M., Sonenshein, A. L., Pero, J. \& Losick, R. (1982). Nucleotide sequences that signal the initiation of transcription and translation in Bacillus subtilis. Mol \& Gen Genet 186, 339-346.

Palva, I. (1982). Molecular cloning of $\alpha$-amylase gene from Bacillus amyloliquefaciens and its expression in Bacillus subtilis. Gene 19, 81-87.

Perego, M., Higgins, C. F., Pearce, S. R., Gallagher, M. P. \& Hoch, J. A. (1991). The oligopeptide transport system of Bacillus subtilis plays a role in the initiation of sporulation. Mol Microbiol 5, 173-185.

Rudner, D. Z., LeDeaux, J. R., Ireton, K. \& Grossman, A. D. (1991). The spoOK locus of Bacillus subtilis is homologous to the oligopeptide permease locus and is required for sporulation and competence. J Bacteriol 173, 1388-1398.

Sambrook, J., Fritsch, E. F. \& Maniatis, T. (1989). Molecular Cloning: a Laboratory Manual, 2nd edn. Cold Spring Harbor, NY: Cold Spring Harbor Laboratory.

Sanger, F., Nicklen, S. \& Coulson, A. R. (1977). DNA sequencing with chain-terminating inhibitors. Proc Natl Acad Sci US A 74, 5463-5467.

Walker, J. E., Saraste, M., Runswick, M. J. \& Gay, N. J. (1982). Distantly related sequences in the $\alpha$ - and $\beta$-subunits of ATP synthase, myosin, kinases and other ATP-requiring enzymes and a common nucleotide binding fold. EMBO J 1, 945-951.

Woodson, K. \& Devine, K. M. (1994). Analysis of a ribose transport operon from Bacillus subtilis. Microbiology 140, 1829-1838.

Received 23 June 1995; revised 29 August 1995; accepted 6 September 1995. 